\title{
Point-of-care ultrasound to complete physical exam and to reach the diagnosis in a young man with syncope
}

\author{
Fatemeh Rasooli ${ }^{1}$, Mehrnoosh Aligholi Zahraie ${ }^{1}$ and Maryam Bahreini2* (D)
}

\begin{abstract}
Background: Cardiac syncope can result from an atrial myxoma due to outflow obstruction. Myxoma is the most common primary cardiac tumor that may cause sudden death and the nonspecific symptoms may make early diagnosis difficult.

Case presentation: A 27-year-old man presented to our emergency department after two episodes of syncope and severe fatigue. He had no complaint of fever, weight loss, sweating, chest pain or dyspnea. Vital signs were within normal limits. A loud heart S1 was detected and normal neck veins. Other systemic examinations including neurological assessment were normal. Electrocardiography showed normal sinus rhythm. An obvious variability in heart rate was noticed on cardiac monitor changing by the patient's position. Point-of-care ultrasonography (PoCUS) showed a large hyperechoic lesion with a well-defined stalk originating from the left atrium (LA). Thus, the patient was transferred to a cardiac surgery center for surgical intervention. Histopathology reported an LA mass compatible with myxoma.
\end{abstract}

Conclusions: Emergency physicians should be familiar with the vague presentations of cardiac tumors to improve patient outcomes. It is beneficial to take advantage of bedside ultrasound for prompt diagnosis and subsequent treatment.

Keywords: Atrial myxoma, Syncope, Outflow obstruction

\section{Background}

Syncope is a sudden temporary loss of postural tone and consciousness resulting from transient decreased cerebral perfusion, seen in nearly $35 \%$ of the general population. It is responsible for high rates of emergency ward visits and hospital admissions annually [1]. The most important causes of syncope include cardiac, neurologic and metabolic disorders, and medication side effects. Moreover, cardiac syncope may result from obstructive, ischemic or conductive heart diseases. This is typically secondary to either a structural or mechanical cardiac

\footnotetext{
*Correspondence: bahreinimaryam@gmail.com; m-bahreini@tums.ac.ir 2 Prehospital and Hospital Emergency Research Center, Department of Emergency Medicine, Tehran University of Medical Sciences, Tehran, Iran

Full list of author information is available at the end of the article
}

problem or due to arrhythmias that alter electrical conduction throughout the myocardium and the latter are recognized as the main cardiac mechanisms for syncope [1]. Atrial myxoma or other cardiac tumors should be considered for prompt diagnosis and treatment regarding the nonspecific symptoms such as weakness, syncope or lightheadedness. In this case, syncope occurred due to an atrial myxoma. Bedside ultrasonography was very helpful to achieve the diagnosis and fast decision-making in this patient.

\section{Case presentation}

A 27-year-old man presented to our emergency department with a history of two episodes of syncope and severe fatigue. He had no complaint of fever, weight loss, sweating, chest pain or dyspnea. Past medical and habitual history was negative. Vital signs were blood 


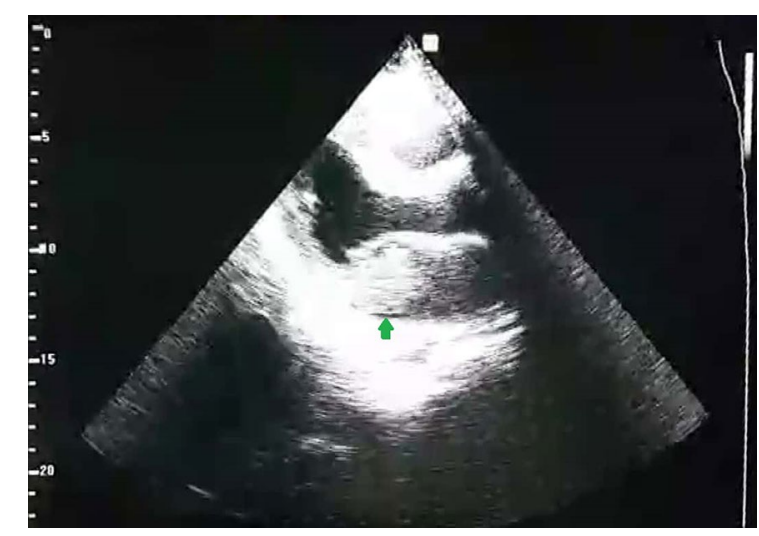

Fig. 1 Transthoracic echocardiography showed a large hyperechoic lesion, located in left atrium in the systolic phase (arrow)

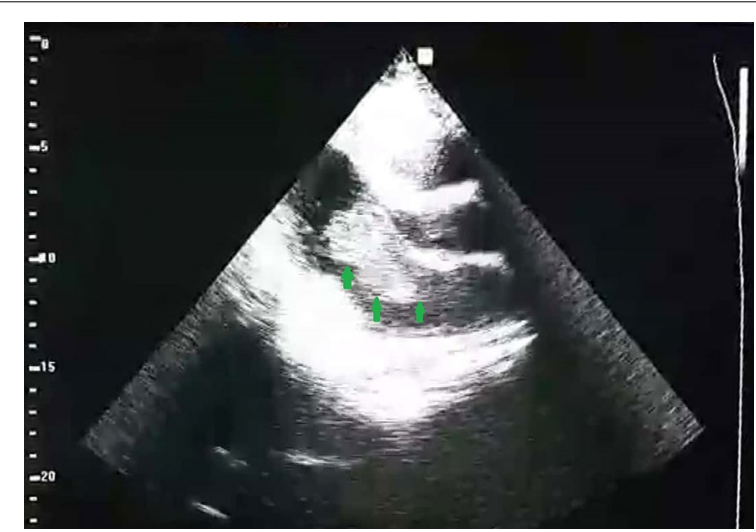

Fig. 2 The highly mobile mass floating into the left ventricle during the diastolic phase (showed by arrows)

pressure 129/75 mmHg, heart rate 75 beats/min, respiratory rate 18 breath/min and oxygen saturation $99 \%$ on room air. He was slightly confused with a fluctuating pattern. A loud heart S1 and normal neck veins were observed. Other systemic examinations including neurological assessment were normal.

Laboratory findings were in normal range. Electrocardiography showed normal sinus rhythm. Brain computed tomography scan and chest X-ray did not show any abnormal findings. Interestingly, an obvious variability in heart rate was noticed on cardiac monitor changing by the patient position. Point-of-care ultrasonography (PoCUS) showed a large hyperechoic lesion with a well-defined stalk originating from left atrium (Figs. 1, 2). Thus, the patient was emergently transferred to a cardiac surgery center for surgical intervention during which a 60-mg mass was removed from his left atrium compatible with myxoma.

\section{Discussion}

Atrial myxoma is the most common primary cardiac tumor that may lead to sudden death [2-4]. Because of the nonspecific symptoms such as weakness and syncope, early diagnosis may be difficult and the symptoms vary according to the tumor location in atrium or ventricle [2,3]. In sporadic cases, atrium is the main involved heart chamber [4]. Myxoma is usually located in left atrium [5].

Dyspnea is usually the most common reported symptom $[3,4]$. Furthermore, the presentation may be an ordinary symptom such as chronic palpitation lasting for 3 months reported by Prousi et al. [6]. Torregrossa et al. reported a case of a 61-year-old man with 1-year history of chronic cough and bilateral low-extremity swelling suspected initially by emergency ultrasound as an atrial mass despite a chronic course [7]. Comparatively, our patient was presented with acuteonset symptoms. Another finding in this case was the younger age in comparison with other studies that reported the mean age of nearly 50 -years for myxoma $[5,8]$. Another study reported unusual manifestations such as acute bilateral limb ischemia in an 18-year-old female by Mathew et al. [9].

However, some more complex situations are also reported such as a simultaneous existence of right coronary artery and left atrial myxoma [10]. Also interestingly, it may be seen as an incidental finding during chest computed tomography in a case with motor vehicle collision reported by Ali et al. [11].

Echocardiography is the method of choice for the diagnosis of atrial myxoma [12]. Despite various clinical presentations, bedside ultrasound and echocardiographic assessment may be beneficial in suspected cases in the emergency department as shown by Raja Rao et al. [13]. In this context, a mobile mass with a narrow stalk in a heart chamber may be suggestive for myxoma or possibly a thrombus [14]. In spite of various clinical manifestations and the need for different therapeutic surgical modalities, the final long-term prognosis is usually fair without significant unfavorable outcomes $[15,16]$ although there are some reports about fatal outcomes and recurrence after operative surgery $[4,8]$.

\section{Conclusion}

Overall, it should be emphasized that emergency physicians should be familiar with the vague presentations of cardiac tumors to improve final outcomes in these 
patients [9]. It is crucial to take advantage of bedside ultrasound for prompt diagnosis and subsequent treatment (Additional file 1).

\section{Supplementary information}

Supplementary information accompanies this paper at https://doi. org/10.1186/s13089-020-00176-5.

Additional file 1. Parasternal long-axis echocardiogram movie showing a highly-mobile mass floating into the left ventricle during the diastolic phase.

\section{Abbreviations}

PoCUS: Point-of-care ultrasonography; LA: Left atrium.

\section{Acknowledgements}

None.

\section{Authors' contributions}

Concept and design: FR, MB, MAZ. Data collection: FR, MB. Writing the article: $F R, M A Z, M B$. Critical revision of the article: FR, MAZ, MB. Final approval of the article: FR, MB, MAZ. All authors read and approved the final manuscript.

\section{Funding}

None.

\section{Availability of data and materials}

None.

\section{Ethics approval and consent to participate}

The ethics of this report have been approved by the University of Medical Sciences Institutional Review Board. This Research involving a human participant meets the declaration of Helsinki principles. Written consent was obtained from the patient.

\section{Consent to publication}

Done.

\section{Competing interests}

The authors declare that they have no competing interests.

\section{Author details}

${ }^{1}$ Department of Emergency Medicine, Tehran University of Medical Sciences, Tehran, Iran. ${ }^{2}$ Prehospital and Hospital Emergency Research Center, Department of Emergency Medicine, Tehran University of Medical Sciences, Tehran, Iran.

Received: 26 December 2019 Accepted: 11 May 2020

Published online: 25 May 2020

\section{References}

1. Benditt DG (2011) Syncope: an overview of diagnosis and treatment. Revista Uruguaya de Cardiología. 26:55-70

2. Yu S-H, Lim S-H, Hong Y-S, Yoo K-J, Chang B-C, Kang M-S (2006) Clinical experiences of cardiac myxoma. Yonsei Med J 47(3):367-371

3. Badui Dergal E, Cordero E, Soberanis N, Verdin R, Arguero R (1992) Cardiac myxoma. A report of 23 cases. Gac Med Mex 128(3):245-252

4. Becker RPRMA, Zalaquett SR, Moran VS, Irarrázaval LI MJ, Arretz VC et al (2008) Cardiac myxoma: clinical characterization, diagnostic methods and late surgical results. Rev Med Chil 136:287-295

5. Cianciulli TF, Cozzarin A, Soumoulou JB, Saccheri MC, Mendez RJ, Beck MA et al (2019) Twenty years of clinical experience with cardiac myxomas: diagnosis, treatment, and follow up. J Cardiovasc Imaging. 27(1):37-47

6. Prousi GS, Moran JV, Biggs RG (2019) Atrial myxoma presenting with palpitations: a case report. Cureus. 11(2):e4093

7. Torregrossa J, Perera P, Mailhot T, Mandavia D (2013) Ultrasound diagnosis of a left atrial myxoma in the emergency department. West J Emerg Med 14(2):130-131

8. Livi U, Bortolotti U, Milano A, Valente M, Prandi A, Frugoni C et al (1984) Cardiac myxomas: results of 14 years' experience. Thorac Cardiovasc Surg 32(3):143-147

9. Mathew R, Agrawal N, Aggarwal P, Jamshed N (2019) Atrial myxoma presenting as acute bilateral limb ischemia. J Emerg Med 57(5):710-712

10. Yazigi G, Sourial K, Hussain ST, Mathias P (2019) Left atrial myxoma associated with malignant anomalous course of right coronary artery: a rare concurrent incidence of two rare diseases. Cureus. 11(4):e4561

11. Ali R, Tahir A, Nadeem M, Rizvi SB (2018) A silent left atrial myxoma: a rare benign cardiac tumor. Cureus. 10(4):e2551

12. Su Y, Song H (2019) Hemorrhage and associated fistula formation in a left atrial myxoma causing coronary artery steal syndrome. Echocardiography. 36(6):1191-1193

13. Raja Rao MP, Prashanth P, Mukhaini M (2011) A large left atrial myxoma detected in emergency department using bedside transthoracic echocardiography. J Emerg Trauma Shock. 4(4):518-520

14. Jang K-H, Shin D-H, Lee C, Jang J-K, Cheong S, Yoo S-Y (2010) Left atrial mass with stalk: thrombus or myxoma? J Cardiovasc Ultrasound. 18(4):154-156

15. Gaisendrees C, Mader N, Sabashnikov A, Schlachtenberger G, Suhr $L$, Wahlers T (2020) Minimally invasive resection of a giant left atrial myxoma: a case report. Perfusion 35(3):263-266.

16. Nehaj F, Sokol J (2018) Outcomes of patients with newly diagnosed cardiac myxoma: a retrospective multicentric study. Biomed Res Int 2018:8320793

\section{Publisher's Note}

Springer Nature remains neutral with regard to jurisdictional claims in published maps and institutional affiliations.

\section{Submit your manuscript to a SpringerOpen ${ }^{\circ}$ journal and benefit from:}

- Convenient online submission

- Rigorous peer review

- Open access: articles freely available online

- High visibility within the field

- Retaining the copyright to your article

Submit your next manuscript at springeropen.com 